\title{
O Processo de Transferência de Tecnologia na Indústria Têxtil
}

\author{
Edi Braga Jr. (I), Marcello Pio (2), Adelaide Antunes (3)
}

\begin{abstract}
This article has the objective to describe and characterize the textile sector's technology transfer process, under the light of the core theoretical concepts, and the sector's dynamics and technological characterization. In addition to the technology transfer process, the article shows the main bottlenecks observed in the process, and possible actions for the involved actors to seek a better execution to the technologic transfer, thus reducing the acquired technology under-utilization, as well as the delay on its full use.
\end{abstract}

Keywords: Textile industry, technologic innovation, transfer of technology.

\section{Resumo}

Este artigo objetiva descrever e caracterizar o processo de transferência de tecnologia do setor têxtil à luz dos conceitos teóricos básicos e da dinâmica e caracterização tecnológica do setor. Além da caracterização do processo de transferência tecnológica, o artigo apresenta os principais gargalos observados no processo e possíveis ações para que os atores envolvidos busquem um maior efetivação da transferência tecnológica, diminuindo, assim, a sub-utilização da tecnologia adquirida ou a demora em sua plena utilização.

Palavras-chave: Setor têxtil, inovação tecnológica, transferência de tecnologia.

(I) Edi Braga Jr. - EQ/UFRJ, E-mail: edibraga@inpi.gov.br Endereço: Rua Mayrink Veiga no 9 - Centro Rio de Janeiro - RJ - Brasil (2) Marcello Pio - DN/SENAI E-mail: marcello.pio@dn.senai.br. Endereço: SBN Quadra 0 I Bloco C, Ed. Roberto Simonsen $4^{a}$ andar. CEP: 70040-903 - Brasília - DF.

(3) Adelaide Antunes - EQ/UFRJ E-mail: adelaide@eq.ufrj.br. Endereço: UFRJ - Centro de tecnologia - bloco E, sala E - 204, Cidade Universitária - CEP: 21949900 - Rio de Janeiro - RJ 


\section{Introdução}

A existência de um grande número de tecnologias empregadas faz com que nenhum país ou empresa consiga desenvolver toda a tecnologia necessária para o aumento da competitividade. Este processo, caso acontecesse, seria altamente complexo e de elevado custo. Logo, a transferência de tecnologia se torna uma ferramenta eficaz para que empresas ou países adquiram as tecnologias necessárias para o seu desenvolvimento.

A transferência de tecnologia é um processo antigo. Como exemplo, pode-se citar a classificação dos estágios evolutivos da humanidade como reflexo da natureza da tecnologia. Os sítios arqueológicos podem indicar a transferência da tecnologia nova ou já estabelecida (Lowe, 1995). A transferência de tecnologia pode ser definida como a tradução e a transferência do conhecimento técnico, utilizado no desenvolvimento de novos produtos ou processos, entre organizações. Este conhecimento está ou pode estar incorporado em equipamentos de produção ou em produtos manufaturados (Mt. Auburn Associates, 1995). Segundo Ramsey (1995), a transferência de tecnologia é um processo formal e legal para um usuário final, e tem por finalidade a comercialização tecnológica. $O$ objetivo desta comercialização é gerar um impacto econômico. A transferência tecnológica pode ser utilizada como uma ferramenta, na tentativa de duas organizações buscarem um objetivo comum, gerando como resultado a plena satisfação das partes. Em um mercado competitivo e altamente veloz nas mudanças de produtos e serviços, a transferência de tecnologia se tornou parte efetiva das estratégias tecnológicas e corporativas das empresas. O desenvolvimento ou compra de uma tecnologia devem ser vistos como uma ação da estratégia tecnológica corporativa de uma empresa. A transferência se inicia quando, ao se analisarem as necessidades de uma indústria ou mercado, identificase uma tecnologia ou combinação de tecnologias para satisfazer tais necessidades. Em outras palavras, a transferência de tecnologia se dá através do compartilhamento de uma invenção ou inovação. Este pode ser feito entre uma agência governamental e uma organização privada, entre organizações privadas ou entre organizações governamentais.As organizações governamentais podem ser instituições de pesquisa e desenvolvimento e universidades. Na transferência entre organizações privadas, deve-se levar em consideração se estas são de países industrializados ou em desenvolvimento.

A transferência de tecnologia pode ser dividida em duas formas distintas. Uma está baseada no desenvolvimento da tecnologia. Neste processo, os paradigmas tecnológicos são modificados pelo processo de inovação de produtos e processos. O outro tipo está baseado na difusão tecnológica. Este tipo abrange a adoção de tecnologias de produtos e processos disponíveis comercialmente e o uso de informações técnicas, oriundas de fontes externas, para a solução de problemas, utilizando os par- adigmas tecnológicos existentes. (Mt.Auburn Associates, 1995).

As instituições responsáveis pela transferência de tecnologia podem ser divididas em instituições fornecedoras de tecnologia (supply-side) e de análise da demanda tecnológica (demandside). As instituições fornecedoras de tecnologia são aquelas que desenvolvem a tecnologia, ou representam as que desenvolvem. Estas instituições procuram por "consumidores" para a tecnologia desenvolvida. Podem-se citar como exemplos, instituições de P\&D, produtores de equipamentos e firmas com patentes para licenciamento ou com licenças vencidas.As instituições de demanda tecnológica atuam em firmas com necessidades tecnológicas, e procuram trazer para essas a tecnologia apropriada. Como exemplo deste tipo de instituição têm-se associações comerciais e instituições de serviços de assistência técnica.

\section{O Processo de Transferência Tecnológica - Uma breve revisão teórica}

Para o National Technology Transfer Center (NTTC) (1999) existem três tipos principais de transferência tecnológica:

Spin-off Technology - Neste tipo de transferência, a tecnologia é desenvolvida por uma organização federal e transferida ao setor privado, a outra agência federal ou a governos locais. Esta tecnologia é do tipo genérica.

Spin-on Technology - Esta transferência se refere às tecnologias viáveis comercialmente, desenvolvidas por organizações privadas, mas com potencial aplicação em organizações públicas.

Dual-Use Technology - Esta se refere ao co-desenvolvimento da tecnologia por uma organização pública e privada. Os custos são divididos entre as organizações, pois ambas serão beneficiadas pela nova tecnologia.

Além dos tipos, este centro considera que a transferência de tecnologia pode ser feita de três formas distintas:

Forma Passiva: Nesta transferência, o receptor da tecnologia pesquisa a tecnologia adequada, através do contato com as pessoas que desenvolveram a tecnologia, ou examinando os resultados de P\&D. Nesta forma, nenhum agente de transferência de tecnologia é envolvido.

Forma Semi-ativa: Neste mecanismo, entra em cena o agente de transferência tecnológica. Este tem como função auxiliar o receptor da tecnologia a identificar a melhor tecnologia disponível. 
Forma Ativa: Esta é a mais cara e mais efetiva forma de transferência de tecnologia. Neste mecanismo, uma pessoa, ou um pequeno grupo, possui a responsabilidade de verificar as possibilidades de utilização de uma determinada tecnologia e se ela é apta a atender às necessidades de mercado. Existe uma interação muito grande entre o setor de P\&D, o mercado e as políticas regulatórias.

O licenciamento, como mecanismo de obtenção de uma nova tecnologia, pode ser utilizado entre duas organizações, através de um contrato legal, onde se definirá o grau de exclusividade na utilização da tecnologia desenvolvida por uma das organizações. A licença de transferência de direito é caracterizada pela exclusividade que o licenciado possui na utilização da tecnologia patenteada. Neste tipo de licença, o licenciador não tem direito ao uso da tecnologia. É praticamente uma venda da patente. $\mathrm{Na}$ licença de exclusividade, o licenciado, além do dono da patente, pode usar a tecnologia patenteada.A licença de nãoexclusividade dá ao licenciado o direito de uso da tecnologia, mas o dono da patente pode conceder a outro o uso desta. Quando uma patente é aprovada, qualquer pessoa está habilitada para o licenciamento, desde que cumpra os termos estabelecidos pelo dono da patente. Neste caso tem-se a licença de direito. Neste mecanismo de transferência, a organização licenciadora deverá fornecer os conhecimentos tácito e explícito, necessários para que o licenciado utilize a tecnologia de forma plena (Lowe, 1995). Este processo envolve três etapas:

a) A transferência da informação: Nesta etapa, ocorre a divulgação da nova tecnologia desenvolvida, através de publicações técnicas. O objetivo é buscar potenciais licenciados.

b) Consolidação do relacionamento: $\mathrm{Na}$ segunda etapa, a organização licenciadora personaliza a informação e inicia um processo de construção de um relacionamento sólido com a organização licenciada.

c) Implementação do processo de transferência.

A transferência de uma determinada tecnologia, para uma organização - empresarial ou não - ou mercado, necessita de uma boa infra-estrutura e de uma forte relação entre o fornecedor da tecnologia e o receptor desta. Isto significa dizer que não basta ao fornecedor transferir fisicamente a tecnologia. Esta deve vir acompanhada de um suporte capaz de fazer com que - receptor utilize plenamente a tecnologia adquirida. Se o receptor não estiver completamente qualificado para absorver as novas informações e para utilizá-las efetivamente, em suas necessidades específicas, devem-se criar mecanismos para que uma interação face a face seja estabelecida. $O$ sucesso deste processo está intimamente ligado à interação e colaboração entre os setores de pesquisa e desenvolvimento (P\&D), de engenharia e o corpo técnico. Para Meyer (1995), além dos setores citados acima, a transferência envolve também o setor de marketing.A transferência de tecnologia está fundamentada não só na transferência de know-how técnico - informações de P\&D, de engenharia e conhecimento de padrões - mas também no conhecimento processual - acordos, utilização de patentes e licenças, etc.

A interação na transferência tecnológica deve ser feita face a face, e a comunicação deve ser clara e feita, normalmente, de forma bidirecional. Em algumas situações, a forma é unidirecional. Nesta interação, o fornecedor da tecnologia deve: discernir o uso da tecnologia para as possíveis aplicações; aumentar a percepção de recursos em potencial e do retorno do investimento desta nova tecnologia; aumentar o número de potenciais receptores da tecnologia desenvolvida; selecionar a forma e o mecanismo apropriado da transferência da tecnologia; estabelecer e utilizar mecanismos para medir o sucesso da transferência tecnológica.

Uma transferência tecnológica efetiva deve levar em conta algumas dimensões externas ao processo em si (Mt. Auburn Associates, (1995). Estas dimensões são:

Novos Sistemas de Gerenciamento: A existência de novos sistemas de gerenciamento - Gestão pela Qualidade Total, Planejamento Estratégico, Técnicas Just-in-time, etc. - faz com que a organização tenha conhecimento das suas necessidades de mercado e tecnológicas. Além disso, ela estará preparada para gerenciar a nova tecnologia adquirida.

Pesquisa de Mercado: A pesquisa de mercado é útil na compreensão do potencial da tecnologia que se pretende adquirir e na verificação de sua viabilidade comercial.

Intensificação das Habilidades: A utilização plena da nova tecnologia dependerá dos conhecimentos técnicos do fluxo produtivo e das soluções de problemas. A empresa receptora da tecnologia deverá ter um processo sistemático de treinamento e atualização das pessoas envolvidas com esta tecnologia. $O$ aprendizado é uma habilidade fundamental para que a transferência tecnológica ocorra de forma efetiva.

Organização do Trabalho:A escolha e a transferência da tecnologia estão intimamente ligadas à organização do trabalho no "chão de fábrica". Uma estrutura extremamente hierarquizada, onde os funcionários não possuem autonomia para solucionar os problemas e com uma rotatividade alta, provavelmente, terá dificuldade na implantação e implementação da tecnologia adquirida. 
Finanças: $O$ gerenciamento das finanças é crítico, não só para o financiamento da nova tecnologia, mas também para investimentos na infra-estrutura necessária.

Cooperação entre firmas:A cooperação entre as empresas pode auxiliar na difusão das novas tecnologias, através do compartilhamento das experiências na utilização destas. Com isto, o processo de transferência de tecnologia para outras empresas vai se tornando gradualmente mais efetivo.

Segundo Brandbury et al. (apud Mt.Auburn Associates, 1995), a atividade de transferência tecnológica, para ser efetiva, deve levar em consideração a combinação entre a tecnologia, a organização receptora e os seus respectivos graus de ajuste e desajuste. $O$ autor considera que 0 desajuste cria uma tensão criativa que estimula $o$ aprendizado e a inovação na aplicação da tecnologia fornecida externamente. Além disso, os contextos tecnológico, social e econômico da organização receptora devem ser levados em consideração. A transferência depende muito do conhecimento tácito. $A$ efetiva transferência requer uma boa comunicação pessoal entre o agente de transferência e o staff da organização receptora. $O$ grau de eficiência da transferência é, também, uma função de como a organização receptora considera a tecnologia, em relação à solução de suas necessidades e de como ela se encaixará no contexto da organização. A motivação é outro item a se considerar em uma efetiva transferência de tecnologia, tanto para a organização fornecedora quanto para a receptora.

Os programas de transferência de tecnologia devem analisar o mercado para o qual a tecnologia será transferida e utilizada. Esta análise deverá abranger:

Informação: A análise da informação deverá observar como o mercado a trata. Isto é, qual a velocidade das mudanças de informações, qual o grau de disponibilidade das informações e como ocorre a difusão das informações nas empresas que atuam neste mercado.

Custos da Transferência: Os programas deverão analisar quais serão os custos da transferência para as empresas do mercado e se elas terão condições de arcar com tais custos.

Recursos Não-Tecnológicos: Os programas de transferência tecnológica devem considerar os recursos que deverão ser desenvolvidos para se ter uma transferência eficiente. Por exemplo: treinamento, reorganização do trabalho, etc.

Estratégias: Para que os programas sejam efetivos, estes devem possuir estratégias para utilização de ferramentas para a transferência da tecnologia. As estratégias devem ser desenvolvidas observando-se as metas e os métodos mais efetivos no uso de tais ferramentas. $O$ objetivo é alcançar o crescimento econômico através do desenvolvimento de uma ou uma série de indústrias.

Serviços: Os programas devem identificar os tipos e o grau de extensão dos serviços oferecidos. Isto é, verificar se estão sendo identificadas as necessidades dos setores envolvidos e se as correções necessárias estão sendo feitas.

$\mathrm{Na}$ transferência de tecnologia entre firmas de países desenvolvidos e em desenvolvimento, deve-se verificar a existência de uma infra-estrutura industrial, que fará com que a utilização da tecnologia adquirida seja plena. Os fornecedores de tais tecnologias devem ter atenção nas condições econômicas, sociais e culturais dos compradores. Edsomwam (1989) considera que, para a transferência tecnológica para países em desenvolvimento ser efetiva, estes devem ter a infra-estrutura necessária. A construção desta deve passar pelo(a): Treinamento dos agentes de transferência e dos usuários da tecnologia; Formação de centros de transferência de tecnologia e manutenção desta; Estabelecimento de centros de treinamento para as tecnologias existentes e para as novas; Criação de procedimentos para o estabelecimento das necessidades reais, com o objetivo de modificar, selecionar e justificar a aquisição das novas tecnologias.

$\mathrm{Na}$ transferência de tecnologia entre empresas de países industrializados, imagina-se que ambas possuam a infra-estrutura necessária para que o processo ocorra a contento. Porém, verifica-se que quando há transferência de uma empresa de um país industrializado para uma empresa de um país em desenvolvimento, nem sempre o receptor da tecnologia está preparado para assimilação e utilização total da tecnologia.

\section{Características Tecnológicas do Setor Têxtil Brasileiro}

O setor têxtil no Brasil pode ser considerado, ainda, como um segmento em transformação. Por ser um dos setores mais antigos do mundo, sempre foi caracterizado como intensivo em mão-de-obra. Contudo, com o desenvolvimento e uso de sistemas de produção automatizados, esta característica está mudando para intensivo em capital. Esta mudança só não é mais rápida devido à grande heterogeneidade das empresas que compõem o setor no Brasil (Braga Jr. \& Hemais, 2002). Como é de tecnologia tradicional, o setor comporta a presença de pequenas, médias e grandes empresas. Esta grande segmentação do setor faz com que haja uma grande diversidade tecnológica entre as empresas. Em uma visão macroeconômica, esta diversificação de tecnologia pode explicar porque países em desen- 
volvimento conseguem competir, normalmente em mercados de artigos mais básicos, com países desenvolvidos. $O$ diferencial da competição dos países em desenvolvimento são os baixos salários e, em alguns casos, o subsídio governamental. A estratégia atualmente utilizada pelos países desenvolvidos é o deslocamento de sua produção para países em desenvolvimento.

A inovação tecnológica para o setor é do tipo incorporada. $O$ desenvolvimento tecnológico é feito basicamente pelos fornecedores, levando o setor a ser classificado como "dominado por fornecedores". A pesquisa e desenvolvimento feitos pelas empresas do setor são voltados para o acompanhamento das tendências de mercado e criação de novos artigos têxteis. O desenvolvimento de novos produtos têxteis é feito em conjunto com os fornecedores de tecnologia.

Devido a competitividade do cenário atual, as empresas do setor buscam a tecnologia com o intuito de produzir e entregar artigos diferenciados e cada vez mais complexos, em um menor tempo possível. Com isto, nota-se que o setor esta deixando de ser intensivo em mão-de-obra para se transformar em intensivo em capital.

Historicamente o setor têxtil nacional sempre teve seu desenvolvimento vinculado às políticas governamentais. Atos como aumento de tarifas de importação, aberturas abruptas de mercado, protecionismo de mercado e incentivos às exportações sempre influenciaram os rumos do desenvolvimento do setor. As empresas nacionais sempre se caracterizaram por uma estrutura familiar e fechada (CETIQT, 2007).

Devido à grande heterogeneidade do setor, existe uma grande variação de idade e de tecnologia nas máquinas e equipamentos utilizados. Apenas as grandes empresas estão capacitadas para investimentos em tecnologias de última geração. Quando essas empresas adquirem novas maquinarias, encontram, nas médias e pequenas empresas, potenciais compradores. Isto faz com que a idade média das máquinas e equipamentos seja elevada.

Até o início dos anos 90 , o setor têxtil nacional trabalhava com um cenário de pouca ou nenhuma competição externa, visto que o Brasil possuía um mercado protegido contra produtos têxteis importados. Por outro lado, o setor era impedido de obter tecnologia importada devido às altas taxas de importação e às constantes desvalorizações da moeda. Este cenário de protecionismo fez com que as empresas não investissem o suficiente na modernização de seus parques industriais e na capacitação de sua mão-de-obra.As empresas se tornaram obsoletas tecnologicamente, sem a possibilidade de competir no mercado internacional. $O$ fator inflacionário também contribuiu para a falta de investimentos em novas tecnologias.

As mudanças tecnológicas são motivadas, basicamente, devido às pressões do ambiente externo. A busca de benefícios econômicos, com agregação de valor e redução dos custos, é a tônica para as inovações ocorridas no setor.

Na busca pela modernização, as empresas irão se deparar com inovações tecnológicas incorporadas em máquinas, produtos químicos e fibras têxteis. $O$ desenvolvimento de máquinas dependerá do sub-setor de atuação. Nos sub-setores de Fiação e Tecelagem, as inovações tecnológicas estão ligadas ao aumento de velocidade e, conseqüentemente, de produção, e ao desenvolvimento de sistemas automatizados de transporte entre as várias etapas do processo produtivo. No sub-setor de Acabamento, as novas tecnologias buscam uma melhora de produtividade, racionalizando a utilização de produtos químicos, água e energia, assim como a qualidade do artigo beneficiado.

O desenvolvimento de produtos químicos de alta qualidade, que busquem atender às necessidades de otimização de processos right-first-time, bem como fornecer ao artigo têxtil características especiais que atendam às exigências de mercado, tem criado uma grande pressão sobre os principais produtores de produtos químicos. As considerações ambientais e de saúde também são levadas em consideração.

A criação de novos produtos têxteis está intimamente ligada ao desenvolvimento de novas fibras. Estas buscam atender a uma demanda de mercado que necessita cada vez mais de fibras de melhor uso, que atendam a determinadas funções especiais e que agreguem valor ao produto.

potencial uso da biotecnologia e o desenvolvimento de sistemas de controle, juntamente com o de máquinas e produtos químicos, estão fazendo com que os processos se tornem mais rápidos, menos agressivos ao meio-ambiente e mais eficientes, no que se refere à qualidade do artigo produzido.

\section{O Processo de Transferência Tecnológica no Setor Têxtil Brasileiro}

O processo de compra da tecnologia está sendo, cada vez mais, descentralizado. Em empresas de grande e médio porte, ela é feita por um colegiado composto por representantes da alta direção, supervisão e departamento de criação. Observa-se que as empresas do setor não possuem uma estratégia tecnológica formal, optando pela troca da tecnologia de forma reativa e pontual. A explicação deste fato pode estar baseada no histórico de proteção à indústria e na crise instalada no setor durante a década de 90 . 
O processo de transferência da tecnologia é comandado pelos fornecedores, na forma de venda e posterior assistência técnica. Eles são os responsáveis pela difusão e implantação da nova tecnologia, através do treinamento das pessoas envolvidas na utilização da tecnologia adquirida. Devido a esta estreita ligação, o relacionamento entre empresas têxteis e fornecedores de tecnologia é de parceria. Este fenômeno é mais intenso entre fornecedores de produtos químicos. $\bigcirc$ grande número de concorrentes, a dinâmica de substituição dos produtos e a velocidade das inovações são fatores que explicam este relacionamento mais forte.

Mesmo não existindo um processo comum de transferência tecnológica, devido principalmente à diversidade tecnológica e estrutural das empresas que compõem o setor, pode-se caracterizar um processo genérico de transferência tecnológica para o setor, através dos seguintes passos: a) Busca de novas tecnologias que visem atender a uma necessidade de mercado, lançar um novo produto ou otimizar processos. b) Verificação da efetividade da nova tecnologia, através de visitas a outras empresas que já possuam tal tecnologia. c) Compra da nova tecnologia na forma de maquinaria, produtos químicos ou novas fibras. d) Difusão da nova tecnologia, através de treinamentos, normalmente iniciados pelo fornecedor e mantidos pela empresa. e) Assistência técnica do fornecedor da tecnologia até que a nova tecnologia já esteja sendo usada de forma plena. $\bigcirc$

\section{Tipo de Assistência Técnica}

Tecnologia da aplicação

Adequação da maquinaria

Treinamento

Acompanhamento do processo produtivo

Atuação para possíveis correções

Construção da máquina

Start -up da máquina

Treinamento

Acompanhamento do processo produtivo

Atuação para possíveis correções

Fibras

Tecnologia da aplicação

Adequação da maquinaria

Treinamento

Acompanhamento do processo produtivo

Atuação para possíveis correções

Tabela I - Relação entre o tipo de assistência técnica e o tipo de tecnologia adquirida

tipo de assistência dependerá da tecnologia adquirida. $A$ tabela I exemplifica as possíveis formas de assistência técnica em relação aos tipos de tecnologia adquirida.

A estratégia dos fornecedores pode ser classificada como de engenharia aplicada (Lowe, 1995), caracterizado pela identificação de soluções tecnológicas para problemas específicos de clientes.

O processo de transferência para o setor é do tipo spin-on techonology (NTTC, 1999) e sua forma de aplicação é passiva, isto é, o receptor da tecnologia pesquisa a tecnologia adequada através do contato com as empresas que desenvolveram a tecnologia. Por se tratar de uma tecnologia tradicional, comprovou-se a teoria que afirma ser o grau de dependência das empresas deste tipo de indústria, em relação ao fornecedor, alto, sendo mais acentuado nos casos onde a infra-estrutura é mais deficiente. Além disso, os fornecedores estão bem estabelecidos no mercado e têm estrutura para acompanhamento das necessidades do setor.

Outra classificação válida para o setor é aquela, onde uma das formas de transferência se dá através da utilização de tecnologias disponíveis comercialmente (Mt.Auburn Associates, 1995). O uso de informações técnicas é oriundo de fontes externas (fornecedores) com o objetivo de solucionar problemas específicos utilizando os paradigmas tecnológicos existentes. A difusão e a absorção da tecnologia ocorrem por assistência técnica. $O$ processo de aprendizagem é feito pelo processo de learning by doing (aprendizagem pelo uso). 
A efetivação do processo de transferência tecnológica confirma alguns itens de análise de Edsomwam (1989), que são:

Treinamento dos agentes de transferência e dos usuários: 0 responsável por este processo é o fornecedor da tecnologia. O treinamento dos agentes de transferência é importante, principalmente quando o fornecedor é estrangeiro.

Existência de centros de treinamento para as tecnologias existentes e para as novas: $O$ setor têxtil nacional possui centros de tecnologia, por exemplo, o SENAI/CETIQT, que têm como finalidade a preparação de profissionais que tenham o conhecimento das principais tecnologias estabelecidas e das possíveis tendências tecnológicas.

Criação de procedimentos:As empresas pesquisadas não possuem procedimentos formais de estratégia tecnológica e transferência tecnológica, com o objetivo de se observarem as reais necessidades do mercado, com o objetivo de modificar, selecionar e justificar a aquisição das novas tecnologias.

Em relação aos fatores externos que poderiam afetar o processo de transferência tecnológica, observa-se que, no caso do setor têxtil, muitos pontos não são levados em consideração. São eles:

Novos sistemas de gerenciamento: As empresas pesquisadas não possuem, de forma sistematizada, sistemas gerenciais mais modernos, como, por exemplo, gestão pela qualidade total, processos formais de planejamento estratégico etc. Isto as torna mais despreparadas para uma análise mais confiável das necessidades de mercado e para o gerenciamento de novas tecnologias.

Pesquisa de mercado:Apesar da maioria das empresas possuírem um processo formal de pesquisa de mercado, nem sempre consegue exprimir com eficiência as novas mudanças. Existem casos nos quais a aquisição de uma nova tecnologia foi comprometida por uma ineficiente pesquisa sobre as tendências de mercado.

Intensificação das habilidades: Foi constatado que a capacitação da mão-de-obra é um dos fatores críticos para o insucesso do processo de transferência tecnológica dentro do setor. $\mathrm{O}$ baixo nível de escolaridade no chão-de-fábrica e a falta de um processo de treinamento sistemático por parte das empresas estudadas fazem com que a absorção e a utilização de uma nova tecnologia fiquem comprometidas. Contudo, observa-se um esforço por parte destas empresas em pelo menos melhorar o nível de escolaridade dos novos funcionários. Pode-se dizer que as empresas do setor estão em uma fase de transição.

Organização do Trabalho: As empresas do setor têxtil possuem, por sua tradição familiar, uma estrutura hierarquizada. A autonomia para soluções de problemas é bastante reduzida, possuindo um turn-over bastante elevado. Isto faz com que a implantação da tecnologia adquirida seja mais demorada. De acordo com a pesquisa, as empresas estão tentando intensificar - fluxo de informações tanto de cima para baixo, quanto de baixo para cima, mas são extremamente tradicionais na forma de passar tais informações. Este aumento pode fazer com que a compreensão da aquisição da nova tecnologia se torne mais clara, evitando problemas de absorção da nova tecnologia pelo não entendimento de sua finalidade. Em relação ao processo de coleta de sugestões, a maioria das empresas não possui um sistema formal, aumentando as possibilidades de que importantes informações sobre as novas ou estabelecidas tecnologias não sejam verificadas.

Finanças: Devido à crise sofrida durante a década de 90 , o setor se encontra em fase de recuperação financeira. Isto pode explicar a dificuldade e a demora para aquisição de novas tecnologias. Contudo, as empresas estudadas têm buscado aumentar a competitividade, através da aquisição de novas tecnologias e infra-estrutura necessárias, ou com recursos próprios ou buscando financiamentos governamentais.

Cooperação entre firmas: Durante o processo de transferência tecnológica a cooperação entre firmas é comum na fase de pesquisa da utilidade industrial da nova tecnologia. Durante esta fase, a empresa receptora da nova tecnologia visita outras empresas, mesmo concorrentes, para verificar in loco o funcionamento da tecnologia.

\section{Considerações Finais}

Toda a aquisição de uma nova tecnologia deve ser precedida de uma preparação técnico-organizacional por parte da empresa receptora. Em um setor que está em fase de transformação - de intensivo em mão-de-obra para intensivo em capital - esta preparação é fundamental para a plena utilização da tecnologia adquirida.Além do fenômeno acima citado, o setor nacional possui a característica de tem passado por períodos turbulentos, que alavancaram o processo de compra de novas tecnologias. A busca muito rápida de novas tecnologias que objetivam aumentar a produtividade, agregar valor aos produtos finais e, conseqüentemente, a competitividade nem sempre levam em consideração a necessidade de um planejamento prévio para a aquisição da nova tecnologia. Como resultado, tem-se a sub-utilização desta.

Este fenômeno foi constatado através de casos que detalham as dificuldades do processo de transferência tecnológical. Os es- 
tudos mostram que as empresas tiveram problemas com a transferência tecnológica, principalmente durante a crise das importações chinesas na década de 90 , por falta de uma infraestrutura para utilização da tecnologia adquirida. As áreas que compõem esta infra-estrutura são: capacitação da mão-de-obra, planejamento da produção e comercialização, sistemas organizacionais e equipamentos de suporte. Dos itens listados acima, observou-se que a capacitação da mão-de-obra é o fator que mais influência tem no sucesso da transferência tecnológica.

Para os fornecedores de tecnologia, um eficiente processo de transferência tecnológica está baseado em um relacionamento de parceria, baseado na confiabilidade técnica e funcional da nova tecnologia comercializada. Neste processo, fornecedores e empresas têxteis devem trabalhar juntos, buscando oferecer ao mercado artigos que atendam aos diversos níveis de exigência dos clientes finais. Contudo, para que este processo ocorra de forma plena, as empresas devem se preparar para receber as novas tecnologias. Itens como capacitação de mãode-obra, planejamento da infra-estrutura necessária para recebimento da tecnologia e manutenção de um sistema formal de captação das necessidades de mercado são fundamentais para uma eficiente transferência.

Devido a já comentada heterogeneidade estrutural e tecnológica das empresas têxteis, uma considerável parcela da mão-de-obra empregada é caracterizada pelo baixo grau de escolaridade e pela falta, nas empresas, de investimentos em treinamentos contínuos. Uma boa parcela dos trabalhadores de "chão de fábrica" recebe apenas o treinamento dado pelo fornecedor, ficando limitado à operação técnica de uma determinada tecnologia. Poucas são as empresas que possuem mecanismos para explorar o conhecimento "tácito" das pessoas envolvidas com a nova tecnologia. $O$ processo de polivalência ainda é pouco incentivado, limitando a ação dos funcionários na compreensão das tecnologias que compõem o fluxo produtivo. Estes fatores somados dificultam o processo de absorção de novas tecnologias. Como conseqüência, a tecnologia adquirida não consegue atender às expectativas de aumento de competitividade. Principalmente nesta fase de expansão da produção e de grandes investimentos na modernização do parque industrial, as empresas deveriam se preocupar com a capacitação de sua mão-de-obra.

A simples compra de uma nova tecnologia não significa o aumento automático da competitividade, sendo que o aprendizado é uma habilidade fundamental para que a transferência tecnológica ocorra de forma efetiva.Apesar de existir um movimento para a melhoria da capacitação da mão-de-obra, a falta de um processo formal e continuado de treinamento, por parte das empresas, indica a baixa preocupação com a capacitação da mão-de-obra para aumento da competitividade.

Além da pouca preocupação com a capacitação da mão-deobra, verifica-se que a maioria das empresas têxteis possui baixos índices de inovações gerenciais e organizacionais. Isto é observado pela quase ausência de sistemas de gestão da qualidade; na difícil integração entre as áreas de planejamento e produção; e na falta de mecanismos para formalizar e reter o conhecimento adquirido.A falta destes processos ocasiona uma maior lentidão no processo de transferência tecnológica.

Neste cenário, os centros de ensino industrial têm um relevante papel na preparação de uma mão-de-obra apta para não só absorver novas tecnologias, mas também gerenciar o processo de transferência, fazendo com que este seja pleno e não ocorra a sub-utilização ou não utilização da tecnologia adquirida. Cabe às empresas criar mecanismos de aprendizagem contínua, mantendo um quadro de funcionários capacitados para operar a nova tecnologia e outras que virão a substituí-la.

\section{Referências}

BRADBURY, M.J., COLLINSHAW., P.S. e MOORHOUSE, S. Como Aproveitar a Tecnologia para obter Vantagens Competitivas. Tradução: Agostinho S. Pacheco. Zêneca Colours. Inglaterra, 1997.

BRAGA Jr., E. O. \& HEMAIS, C. A. A Indústria Têxtil Frente a Concorrência Internaciona - Abordagem estratégical ". Revista ABTT: São Paulo. no 000, ano 01, 2002.

CETIQT. Globalização da Economia têxtil. SENAI-CETIQT. Rio de Janeiro, 2007.

EDOSOMWAM, J.A. Integranting Innovation and Technology Management. John Wiley \& Sons. New York, 1989.

LOWE, P. The Management of Technology: perception and oportunities. Chapman \& Hall. Londres, 1995.

MEYER, H.A., Technology Tranfer !!??!. Pax Technology Tranfer Home Page. endereço eletrônico http://www.pax.co.uk/ttdefine.html. . capturado em 16 de outubro de 1999

MT. AUBURN ASSOCIATES. Technology Transfer to Small Manufactures: A Literature Review. Relatório final. Somerville, 1995. endereço eletrônico http://www.cherry.gatech.edu/mot/ index.htm. capturado em 23 de novembro de 1999. 
NATIONAL TRANFER CENTER. How to transfer technology. endereço eletrônico http://www.nttc.edu/training/guide/ secc00.html. capturado em 16 de outubro de 1999.

PIO, M. J.A Inovação Tecnológica e o Processo de Transferência de Tecnologia no Setor Têxtil.Tese de Mestrado apresentada ao Curso de pós-graduação em Tecnologia de Processos Químicos e Bioquímicos. Escola de Química da Universidade Federal do Rio de Janeiro, setembro de 2000.

PIO, M.J., BRAGA JÚNIOR, E.,ANTUNES,A.M.S, HEMAIS, C.A. O Impacto das Inovações Tecnológicas sobre a Cadeia Produtiva Têxtil. artigo apresentado no XIX Congresso Nacional de Técnicos Têxteis, Fortaleza, setembro de 2000.

RAMSEY, L. Technology Transfer !!??!. Pax Technology Transfer Home Page. endereço eletrônicohttp:// www.pax.co.uk/ttdefine.html. . capturado em 16 de outubro de 1999.

\section{Sobre os Autores}

Edi Braga Jr. Doutorando em Processos Químicos e Bioquímicos pela Escola de Química da Universidade Federal do Rio de Janeiro (UFRJ - EQ), Pesquisador do Instituto Nacional de Propriedade Industrial (INPI).

Adelaide Maria de Souza Antunes. Coordenadora do Sistema de Informação da Indústria Química (SIQUIM) e Professor Titular dos cursos de graduação e pós-graduação da Escola de Química da Universidade Federal do Rio de Janeiro (UFRJ $\mathrm{EQ)}$.

Marcello José Pio. Doutor em Ciências pela Escola de Química da Universidade Federal do Rio de Janeiro, Pesquisador da Unidade de Tendências e Prospecção do Departamento Nacional do SENAI (CEP: 70040-903 - Brasília/DF, Brasil). 